J. Product. \& Dev., 17(1):65- 77(2012)

\title{
VIABILITY OF BISECTED RABBIT EMBRYOS AFTER CRYOPRESERVATION USING VITRIFICATION
}

\author{
A.M. Hussein ; E.M.E. El-Siefy; M.E. Omara and M.A. El-Sherbieny
}

Animal Production Research Institute, Agriculture Research Center, Giza, Egypt.

\section{ABSTRACT}

To study the effects of developmental capacity after in vitro culture of intact and demi-embryos of rabbit in fresh case or after cryopreservation using vitrification technique, total 89 embryos at morula and blastocyst stages recovered from 16 does. Compaction rabbit embryos maintained intact (control) were compared with bisected embryos using a simplified splitting protocol at fresh or vitrified thawed embryos. The survivability of intact embryos and demi-embryos were evaluated after 24 hours of in vitro culture by development ability and morphological assessment. The percentage of development after 24 h of in vitro culture was higher $(P<0.05)$ in fresh intact embryos than in fresh bisected embryos, either at morula (80 vs. $56 \%$ ) or blastocyst ( 84.6 vs. 63.6\%) stages. In case of intact or bisected embryos, percentage of development after $24 \mathrm{~h}$ of in vitro culture was insignificantly higher in embryos at blastocyst than at morula stages. The percentage of development after 24 h of in vitro culture was higher $(P<0.05)$ for vitrified intact embryos than for vitrified bisected embryos, either at morula (61.5 vs. $45.0 \%)$ or blastocyst (75.0 vs. $42.1 \%)$ stages. In case of intact embryos, percentage of development after $24 \mathrm{~h}$ of in vitro culture was higher $(P<0.05)$ for embryos at blastocyst than at morula stages. However, the percentage of development after $24 \mathrm{~h}$ of in vitro culture was nearly similar in vitrified bisected embryos, either at morula or at blastocyst stages.

In conclusion, bisection and vitrification can be used for rabbit embryos, but embryonic stage and cryopreservation are limiting factors in the success of these procedures.

Keywords: Rabbit, embryo, bisection, developmental capacity, in vitro culture. 


\section{INTRODUCTION}

Mammalian embryo splitting has successfully been established in farm animals. Embryo splitting is safely and efficiently used for assisted reproduction in several livestock species. Splitting embryos could increase the number of embryos available for transfer. Human embryo splitting has been reported recently (Karl and Mike, 2010) and embryo splitting may be more realistic approach to creating pairs of genetically identical monkeys (Schramm and Paprocki, 2004).

It is known that the pregnancy rate resulting after transfer of bisected embryos is lower than after transfer of whole embryos. The main reason is the reduced cell number in the demi-embryo which is less than half of that in the intact embryo. The commonly used method for obtaining monozygous twins in mammals is embryo splitting (Willadsen and Godke., 1984 and Baker, 1985) applied to embryos at post compaction, i.e.; the morula and blastocyst stages. Usually embryo splitting is performed with a metal micro-blade or a glass microneedle (Mertes and Bondioli, 1985).

Since a number of blastomeres are damaged as a result of the procedure of splitting, the cell losses depend mostly on the stage (Skrzyszowska and Smorag, 1989) and quality (Brem et al., 1984) of the embryo and precision of the microsurgery. The destruction of cells during splitting could be one of the main reasons for the lower pregnancy rate seen following the transfer of bisected embryos. The development of an alternative method reducing cell losses during bisection could improve the demi-embryo transfer technology.

Since the first reports of embryo bisection in cattle (Willadsen et al., 1981 and Ozil et al., 1982), the technique has been used in this species to produce identical twins (Willadsen and Polge, 1981; Willadsen and Godke., 1984 and Bredbacka, 1996), facilitate embryo sexing (Picard et al., 1985 and Bredbacka et al., 1994), and increase the number of transferable embryos (Leibo and Pall, 1987; Gray et al., 1991 and Kippax et al., 1991), as has been reviewed (Picard and Betteridge 1989; Willadsen, 1982).

Embryo bisection has, therefore, found commercial application in livestock production (Gray et al., 1991 and Bredbacka, 1996), particularly after simplification of the technique (Utsumi and Iritani, 1990 and Bredbacka, 1996). Attempts to improve the bisection technique have included the use of surrogate zonae pellucidae (Voelkel et al., 1984; Warfield et al., 1986), modification of the micromanipulation medium (Suzuki and Shimohira, 1986; Herr et al 1988 and Szell and Hudson, 1991), and selection of embryos at particular ages and developmental stage (Williams et al., 1984 and McEvoy and Sreenan, 1990). 
Therefore, the objectives of the present study were to examine the effects of developmental stage and cryopreservation on the in vitro survival of intact and demi-embryos

\section{MATERIALS AND METHODS}

This study was carried out at the International Livestock Management Training Center (ILMTC), and Sakha Animal Production Research Station, belonging to the Animal Production Research Institute, Agricultural Research Center, Ministry of Agriculture, Egypt,

\section{Animals:}

Sixteen mature New Zealand White (NZW) rabbit does having 1-2 years of age were used as embryo donors in this study. All does were fed commercial pelleted diet and kept under the same environmental conditions. They were individually caged for 3-5 weeks prior to start of the experiment to avoid pseudo-pregnancy.

\section{Media:}

The medium used for embryo culture was serum-free M-199 containing Earle's salts, $2.5 \mathrm{mM} \mathrm{Na}$ pyruvate, $1 \mathrm{mM}$ L-glutamine, $0.5 \%$ penicillin-streptomycin, and $0.1 \mathrm{mg} / \mathrm{mL}$ polyvinyl alcohol (MW 30,000 to 70,000 ; Sigma), the $\mathrm{pH}$ was adjusted to 7.4 and the osmolality to 280 $\mathrm{mOsm} / \mathrm{kg}$. Further manipulation of embryos was performed in drops of serum-free Dulbecco's phosphate buffered saline (DPBS) so that embryos adhered to the bottom of the Petri dishes.

Conditioned M-199 medium prepared by the method outlined by (Mermillod et al. 1993) was used to culture the demi -embryos. The culture was maintained at $38.5^{\circ} \mathrm{C}$ in a humidified atmosphere of $5 \% \mathrm{CO}_{2}$ in air. The cells grew to confluence; the confluent mono-layers were washed 3 times with serum-free M-199 and then cultured in the same medium until recovering after $48 \mathrm{~h}$ of conditioning.

\section{Superovulation and embryo recovery:}

Rabbit does were super-stimulated with a single injection of 75 IU of PMSG (Folligon, Intervet, Holand). After $72 \mathrm{~h}$ of PMSG injection, ovulation was induced by $100 \mathrm{IU}$ of HCG (Pregnyl) injected into ear vein followed by mating with fertile buck (two consecutive inseminations). Total of 98 embryos were flushed from the oviduct and uterus of slaughtered does with Dulbecco's phosphate-buffered saline solution (PBS, Sigma) supplemented with $5 \%$ heat-inactivated fetal calf serum (FCS, Sigma) and 
$50 \mu \mathrm{g} / \mathrm{ml}^{-1}$ of gentamicin sulphate. Embryos at morula and blastocyst stages were recovered after $48 \mathrm{~h}$ and $72 \mathrm{~h}$ post-coitus.

The recovered embryos were classified according to their developmental stage and morphological appearance under a microscope, good quality embryos, according to the criteria established by Lindner and Wright (1984) for embryos with presence of a normal mucin coat. Embryos at morula stage with uniform sized blastomeres and blastocyst were considered suitable for splitting or freezing.

\section{Bisection and classification of embryos:}

Bisection was performed in $60-\mu \mathrm{L}$ drops of DPBS at room temperature using a micromanipulator with an attached microsurgical steel blade but without a holding pipette (Figure 1). For this, the embryos were washed twice in DPBS and transferred to the micromanipulation drop. Only embryos at morula and blastocyst stages were selected and bisected by slowly lowering the micro-blade and then gently moving it to embryo. Bisection method is illustrated in Figure 1, started with intact embryo (phase 1) to bisected embryo (phase 6). In the case of blastocysts, care was taken to orientate the embryos, so that the inner cell mass (ICM) was divided as evenly as possible. After completing the bisection, DPBS containing $10 \%$ fetal calf serum was added to the micromanipulation drop to allow the demi-embryos to float free of the floor of the dish. After $24 \mathrm{~h}$ of culture in conditioned M-199 medium, the demiembryos that redeveloped into three categories. Divided embryos, without a zona pellucida, were washed 3 times with conditioned M-199 and cultured in $10 \mu \mathrm{L}$ of the same medium under mineral oil. The quality of demi-embryos was morphologically evaluated $24 \mathrm{~h}$ after bisection.

Bisected embryos were classified subjectively for quality using the criteria previously described in analogous studies in pigs (Nagashima et al., 1989, Reichelt and Niemann, 1994). Category I: excellent embryos had a clearly defined blastocoel, very few degenerated cells $(<10 \%)$, and a clearly visible ICM. Category II: fair embryos were also blastocysts but 10 to $20 \%$ of their cells appeared to be degenerated or the ICM was not clearly visible. Category III: degenerated embryos showed no visible ICM and blastocoel, and contained a large number of degenerated cells $(>20 \%)$. For the purposes of the present study, embryos classified into categories I and II were deemed viable and transferable. 

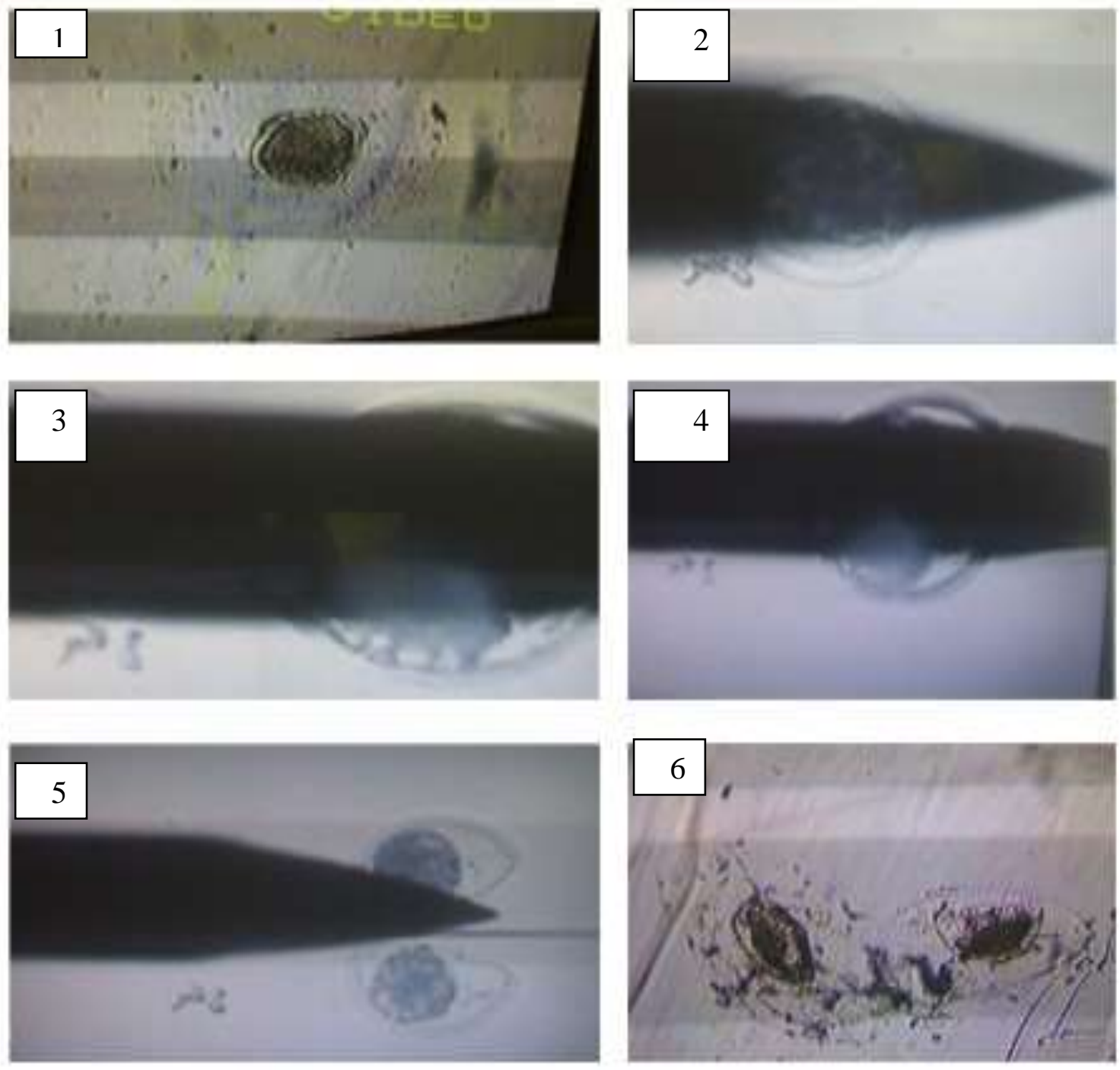

Figure 1: Steps of embryo splitting technique using micromanipulator with metal blade (X 200).

Step (1): Shows intact embryo at morula stage before bisection. Steps(2-4): Show microsurgical steal blade of the micromanipulator upper an intact embryo immediately before bisection.

Step (5): Shows the final stage of embryo bisection.

Step(6): Shows two embryos produced by bisecting an intact embryo at morula stage. 


\section{Vitrification by modified Open Pulled Straw (mOPS) technique:}

Cryopreservation was done using mOPS described by Lopez-Bejar and Lopez-Jatius. (2002). Steps and solutions were done according to Naik et al. (2005). Sucrose stock solution was prepared by dissolving $10.27 \mathrm{~g}$ of sucrose in $20 \mathrm{ml}$ of HEPES buffered TCM-199 (TCM 199H). This medium was stored in $50 \mathrm{ml}$ plastic tubes at $4^{\circ} \mathrm{C}$ till used. Holding medium for vitrification was prepared by supplementing TCM-199H with $20 \%$ fetal calf serum (FCS, v/v) and $50 \mu \mathrm{g} / \mathrm{ml}-1$ of gentamicin sulphate.

Two vitrification solutions (VS) were prepared, the $1^{\text {st }}$ solution (VS-I) contained $10 \%$ ethylene glycol (EG) and 10\% dimecyle sulfoxide (DMSO) was prepared, on day prior to use, by mixing EG, DMSO and the holding medium at a ratio of $1: 1: 8$ and stored at $4^{\circ} \mathrm{C}$. The $2^{\text {nd }}$ one (VS-II) contained 20\% EG, 20\% DMSO and 0.6 M sucrose was prepared on the day prior to use by mixing EG, DMSO, FCS and sucrose stock solution at a ratio of $1: 1: 1: 2$ and stored at $4^{\circ} \mathrm{C}$.

Also, two cryoprotective diluents were prepared, the $1^{\text {st }}$ diluent (CPD-I) had the same composition as VS-I but contained $0.3 \mathrm{M}$ sucrose in addition. This was prepared by mixing equal volumes of VS-II and the holding medium. The $2^{\text {nd }}$ one (CPD-2) was prepared by mixing CPD-I and holding medium at a ratio of 1:3.

Good quality embryos at morula and blastocyst stages were equilibrated for $5 \mathrm{~min}$ in the holding medium prior to OPS vitrification. In order to vitrify 3-5 embryos, they were initially placed in VS-I for $2 \mathrm{~min}$. Subsequently, the embryos were consecutively transferred into three droplets of VS-II for $10 \mathrm{~s}$ each. During the last $10 \mathrm{~s}$ of exposure to VS-II, open end of the pulled straw was placed on the surface of the third droplet. The embryos entered into the straw by capillary action. Immediately after loading, the straws were plunged vertically into liquid nitrogen (LN) and stored for up to 2 months.

\section{Thawing method:}

Straws containing embryos were taken out of $\mathrm{LN}$ and the open end of straw was immersed vertically in $1.2 \mathrm{ml}$ of VS-CPD-I solution. The vitrification medium became liquid within 2-4 seconds and the contents of the straw were then released into the well by gentle blowing using a mouth pipette. One minute after, they were transferred into VS-CPD-II solution for $5 \mathrm{~min}$. Finally, they were washed twice in holding medium for $5 \mathrm{~min}$ each.

\section{In vitro culture of cryopreserved embryos:}

For in vitro culture of rabbit embryos, bicarbonate buffered tissue culture medium (TCM 199B) was supplemented with 15\% heat inactivated 
FCS and $50 \mu \mathrm{g} / \mathrm{ml}-1$ of gentamicin sulphate and stored at $4^{\circ} \mathrm{C}$ for up to one week. It was warmed in a carbon dioxide incubator for a minimum of one $h$ prior to culture of embryos. After removal of the cryoprotectants, morphology under a microscope, embryos with uniform blastomeres were regarded as good embryos suitable for culture. Damaged embryos exhibiting lysed blastomeres were discarded.

Groups of 3-5 good embryos were placed in one $\mathrm{ml}$ of embryo culture medium under mineral oil (Sigma Aldrich Chemie, Steninheim, Germany) and incubated at $38.5^{\circ} \mathrm{C}$ in a humidified atmosphere of $5 \% \mathrm{CO}_{2}$ in air. Checks for developmental stage were done after $24 \mathrm{~h}$. The demi-embryos were classified according to morphological criteria (number of degenerated cells, development of blastocoel and inner cell mass), good quality embryos at the end of culture period was considered suitable for transfer and indicator of success of splitting, freezing and thawing of embryos.

\section{Statistical analysis:}

Chi-square test was used according to Snedecor and Cochran (1982) to determine differences between rates of survival and development of whole and bisected embryos at different stages.

\section{RESULTS AND DISCUSSIONS}

\section{In vitro culture of whole or bisected fresh embryos:}

Results in Table (1) show that the percentage of development after $24 \mathrm{~h}$ of in vitro culture was significantly $(\mathrm{P}<0.05)$ higher in fresh intact embryos than in fresh bisected embryos, either at morula ( $80 \mathrm{vs} .56 \%$ ) or blastocyst ( 84.6 vs. $63.6 \%$ ) stages.

In case of intact or bisected embryos, percentage of development after $24 \mathrm{~h}$ of in vitro culture was insignificantly $(\mathrm{P}>0.05)$ higher in embryos at blastocyst than at morula stages. Generally, the intact embryos presented greater percentage of alive cells than cultivated hemi-embryos.

Table 1: Development in culture of fresh whole or bisected embryos at morula and blastocyst stages.

\begin{tabular}{|l|c|c|c|c|}
\hline \multirow{2}{*}{$\begin{array}{c}\text { Embryo } \\
\text { stage }\end{array}$} & \multirow{2}{*}{$\begin{array}{c}\text { Type of } \\
\text { embryo }\end{array}$} & \multirow{2}{*}{$\begin{array}{c}\text { Number of } \\
\text { embryos }\end{array}$} & \multicolumn{2}{c|}{ Development in culture } \\
\cline { 4 - 5 } Morula & Whole & 15 & 12 & n \\
\hline \multirow{2}{*}{ Blastocyst } & Bisected & 25 & 14 & $80.0^{\mathrm{a}}$ \\
& Whole & 13 & 11 & $86.0^{\mathrm{b}}$ \\
\hline & Bisected & 22 & 14 & $63.6^{\mathrm{a}}$ \\
\end{tabular}

Means denoting with different superscripts within the same column are significantly $(\mathrm{P}<0.05)$ different. 
Similar results were obtained in rabbits by Celestinos and Gatica (2008), who found that the corresponding percentages were $96 \%$ for control intact embryos versus $74 \%$ for fresh bisected embryos, and all the observed differences were highly significant $(\mathrm{P}<0.001)$. The present results indicated difference in developmental capacity between bisected fresh embryos and intact fresh ones following in vitro culture.

The percentage of development obtained with fresh bisected embryos at morula or blastocyst stages, being 56.0 and $63.6 \%$, respectively, is in the range reported following in vitro culture of demi-embryos (Bredbacka et al., 1994). In bovine embryos, Bredbacka (1996) found higher proportion of viable cells in bisected morulae compared with bisected blastocysts (75.5 vs. $70.0 \%)$.

\section{In vitro culture of whole or bisected vitrified embryos:}

Results in Table (2) show that the percentage of development after $24 \mathrm{~h}$ of in vitro culture was significantly $(\mathrm{P}<0.05)$ higher in vitrified intact embryos than in vitrified bisected embryos, either at morula (61.5 vs. $45.0 \%)$ or blastocyst (75.0 vs. $42.1 \%)$ stages. In case of intact embryos, percentage of development after $24 \mathrm{~h}$ of in vitro culture was significantly $(\mathrm{P}<0.05)$ higher in embryos at blastocyst than at morula stages. However, the percentage of development after $24 \mathrm{~h}$ of in vitro culture was nearly similar in vitrified bisected embryos, either at morula or at blastocyst stages. Similarly, Celestinos and Gatica (2008) found that the percentages of development after $24 \mathrm{~h}$ of in vitro culture was significantly $(\mathrm{P}<0.001)$ higher in vitrified intact $(36 \%)$ than in vitrified bisected $(10 \%)$ embryos. The obtained results indicated higher developmental capacity for fresh (Table 1) than vitrified (Table 2) and intact ones following in vitro culture, either at morula or blastocyst stages.

Table 2: Development in culture of whole or bisected embryos at morula and blastocyst stages post-vitrification.

\begin{tabular}{|l|c|c|c|c|c|}
\hline \multirow{2}{*}{$\begin{array}{c}\text { Embryo } \\
\text { stage }\end{array}$} & \multirow{2}{*}{$\begin{array}{c}\text { Type of } \\
\text { embryo }\end{array}$} & \multirow{2}{*}{$\begin{array}{c}\text { Number of } \\
\text { vitrified } \\
\text { embryos }\end{array}$} & $\begin{array}{c}\text { Number of post- } \\
\text { thawed embryos }\end{array}$ & \multicolumn{2}{|c|}{$\begin{array}{c}\text { Development in } \\
\text { culture }\end{array}$} \\
\cline { 5 - 7 } Morula & Whole & 13 & 13 & 8 & $61.5^{\mathrm{b}}$ \\
& Bisected & 21 & 20 & 9 & $45.0^{\mathrm{c}}$ \\
\hline \multirow{2}{*}{ Blastocyst } & Whole & 12 & 12 & 9 & $75.0^{\mathrm{a}}$ \\
& Bisected & 22 & 19 & 8 & $42.1^{\mathrm{c}}$ \\
\hline
\end{tabular}

: Means denoting with different superscripts within the same column are significantly $(\mathrm{P}<0.05)$ different. 
The present study shows that acceptable results can be achieved following in vitro culture of rabbit embryos that have been bisected but that the survivability of such embryos seems to be reduced following vitrifiedthawing. There were no difference in developmental capacity between biopsied embryos at both morula and blastocyst stages following in vitro culture. However the level of survival was overestimated using in vitro culture systems compared to survival after embryo transfer in agreement with other reports (Gustafsson et al., 1994).

It is generally accepted that freezability of embryos is reduced following splitting. In this respect, Bredbacka et al., (1994) reported that survival rates were lower for frozen-thawed demi-embryos (52\%) compared with $60 \%$ for fresh embryos. Also, Vajta et al. (1997) report a survival rate of $86 \%$ for biopsied vitrified-thawed embryos versus $69 \%$ for vitrifiedthawed biopsied embryos. The variation in developmental capacity between fresh and vitrified intact or bisected embryos is associated with loss in blastomeres during splitting and cryopreservation. A number of cells (around 10\%) are shown to be damaged due to the splitting procedure.

The number of cells in an embryo had no effect on cell viability. Apparently the developmental stage effect can be contributed to morphological changes in the embryo rather than to the increase of cell associated with it (Bredbacka (1994). The developmental stage effect found in this study was expressed in a higher proportion of viable blastocysts as compared to morulae. This difference may be of minor relevance for practical purpose, as demi-blastocyst develop equally well or better (Williams and Godke., 1984) than demi-morulae following transfer, possible because blastocysts loss fewer cells (Bredbacka, 1994).

In conclusion, bisection and vitrification can be used for rabbit embryos, but embryonic stage or cryopreservation are limiting factors in the success of these procedures.

\section{REFERENCES}

Baker R. D. (1985). Commercial splitting of bovine embryos. Theriogenology; 23: 3-12.

Bredbacka P., Vehnala R., Peippo J. and Bredbacka K. (1994). Survival of biopsied and sexed bovine demi-embryos. Theriogenology; 41:1023-1031.

Bredbacka P. (1996). Production of calves following nonsurgical transfer of fresh and refrigerated bovine demi-embryos. Agriculture of Food Science Fin., 5:521-527. 
Brem G., Kruff B., Szilvassy B., Tenhumberg H. (1984). Identical Simmental twins through microsurgery of embryos. Theriogenology. 21: 225 (Abst.).

Celestinos, M. and Gatica, R. (2008). In vitro viability of split rabbit embryos before and after vitrification. 9th World Rabbit Congress, June 10-13, Verona, Italy.

Gray K.R., Bondioli K.R. and Betts C.L. (1991). The commercial application of embryo splitting in beef cattle. Theriogenology; 35:37-44.

Gustafsson H., Jaakma U., Shamsuddin M. (1994). Viability of fresh and frozen-thawed biopsied bovine embryos. Acta Vet. Scand., 35: 217222.

Herr C., Holt N. and Reed K.C. (1988). Effect of sucrose and calcium in the splitting medium on survivalof quartered ovine morulae. Proc Ann ConfAust Soc Reprod Biol; 20:10.

Karl Illmensee.; Mike Levanduski (2010). Embryo splitting. Middle East Fertility Society Journal, 15: 57-63.

Kippax I.S., Christie W.B. and Rowan T.G. (1991). Effects of method of splitting, stage of development and presence or absence of zona pellucida on foetal survival in com mercial bovine embryo transfer of bisected embryos. Theriogenology; 35:25-35.

Leibo S.P. and Pall W. F. (1987). Increase in production of pregnancies by bisection of bovine embryos. Theriogenology; 27:245 abstr. 894

Lindner G.M. and Wright W.W. Jr. (1984). Bovine embryo morphology and evaluation. Theriogenology; 20:407-416.

Lo'pez-Be'jar M. and Lo'pez-Gatius F. (2002). Nonequilibrium cryopreservation of rabbit embryos using a modified (sealed) open pulled straw procedure. Theriogenology; 58:1541-52.

Mermillod P., Vansteenbrugge A., Wils C., Mourmeaux J.L., Massip A. and Dessy F. (1993). Characterization of the embryotrophic activity of exogenous protein-free oviduct-conditioned medium used in culture of cattle embryos. Biol. Reprod., 49:582-587.

Mertes P.C. and Bondioli K.R. (1985). Effect of splitting technique on pregnancy rate from half embryos. Theriogenology; 23: 209 Abstr.

McEvoy T.G. and Sreenan J.M. (1990 ). Effect of embryo quality and stage of development on the survival of zona pellucida-free cattle demi-embryos. Theriogenology; 33:1245-1253.

Nagashima 'H., Kato Y. and Ogawa S. (1989). Microsurgical bisection of porcine morulae and blastocysts to produce monozygotic twin pregnancy. Gamete Research; 23:1-9. 
Naik B.R., Rao B.S., Vagdevi R., Gnanprakash M., Amarnath D. and Rao V.H. (2005). Conventional slow freezing, vitrification and open pulled straw (OPS) vitrification of rabbit embryos. Animal Reproduction Science; 86:329-38.

Naik B.R., Rao B.S., Vagdevi R., Gnanprakash M., Amarnath D. and Rao V.H. (2005). Conventional slow freezing, vitrification and open pulled straw (OPS) vitrification of rabbit embryos. Animal Reproduction Science; 86:329-38.

Ozil J.P., Heyman Y. and Renard J.P.(1982). Production of monozygotic twins by micromanipulation and cervical transfer in the cow. Vet. Research; 110:126-127.

Picard L. and Betteridge KJ. (1989). The Micromanipulation Of Farm Animal Embryos. In: Babiuk LA, Phillips JP (eds), Animal Biotechnology, Comprehensive Biotechnology First Supplement. Toronto: Pergamon Press,141-178.

Picard L., King W.A. and Betteridge K.J. (1985). Production of sexed calves from frozen-thawed embryos. Vet. Research; 117:603-608.

Reichelt B. and Niemann H. (1994). Generation of identical twin piglets following bisection of embryos at the morula and blastocyst stage. Journal of Reprod Fertil; 100:163-172.

Schramm, R.D.; A.M.Paprocki (2004). Strategies for the production of genetically identical monkeys by embryo splitting. Reproductive Biology and Endocrinology. 2:38.

Skrzyszowska M. and Smorag Z. (1989). Cell loss in bisected mouse, sheep and cow embryos. Theriogenology; 32: 115-122.

Snedecor, G. W. and W. G. Chochran (1982). Statistical Methods. $6^{\text {th }}$ ed., Iowa State Univ., Press Ames, Iowa, USA.

Suzuki T. and Shimohira I. (1986). Viability in frozen-thawed bovine embryos bisected in sucrose: a preliminary report. Theriogenology; 26:333-339.

Szell A. and Hudson R.H.H. (1991). Factors affecting the survival of bisected sheep embryos in vivo. Theriogenology; 36:379-387.

Utsumi K. and Iritani A. (1990). Production of cattle identical twins by splitting blastocysts using a metal microblade. Theriogenology; 33:341.

Vajta G., Booth P.J., Holm P., Greve P. and Callesen H. (1997). Successful vitrification of early stage bovine in vitro produced embryos with the open pulled straw (OPS) method. Cryo Letters;18:191-5. 
Voelkel S.A., Humes P.E. and Godke R.A. (1984). Pregnancy rates resulting from non-surgical transfer of micromanipulated bovine embryos. Proc 10th Int Congr Anim Reprod AI; 10:251- 253.

Warfield S. J., Seidel G.E. Jr. and Elsden R.P. (1986). Transfer of bovine demi-embryos with and without zonae pellucidae. Theriogenology; 25:212 abstr.

Willadsen S.M. (1982 ). Micromanipulation Of Embryos Of The Large Domestic Species. In: Adams CE (ed.), Mammalian Egg Transfer. Boca Raton, FL: CRC Press, 185-210.

Willadsen, S. M. and Godke, R.A. (1984). A simple procedure for the production of identical sheep twind. Vet. Research; 114: 240-242.

Willadsen S.M. and Polge C. (1981). Attempts to produce monozygotic quadruplets in cattle by blastomere separation. Vet. Research; 108:211-213.

Willadsen S.M., Lehn-Jensen H., Fehilly C.B. and Newcomb R. (1981). The production of monozygotic twins of preselected parentage by micromanipulation of non-surgically collected cow embryos. Theriogenology; 15:23-29.

Williams T.J., Elsden R.P. and Seidel G.E. Jr. (1984). Pregnancy rates with bisected bovine embryos. Theriogenology; 22:521-531. 


\section{قابلية أجنة الأرانب للحياة بعد التقسيم و الحفظ باستخدام طريقة التزجيج}

أحمد محمد أحمد حسين، الشناوي محمد الثناوي الصيفي- محمد عيسى عمارة-

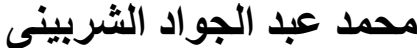
معهد بحوث الإنتاج الحيوانى - مركز البيرينى البحث الزراعيهـ الجيزة - ج.م.ع.

تم إجر اء هذا البحث لدر اسة تأثير ات نمو وتطور الأجنة معمليا سواء الطازجة أو بعد

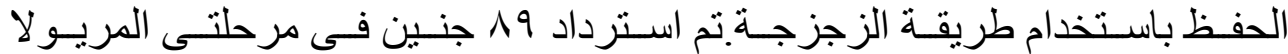

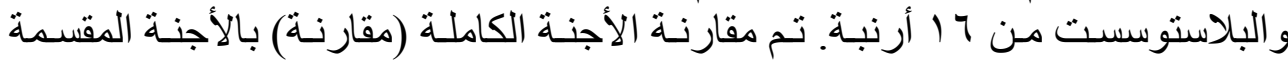

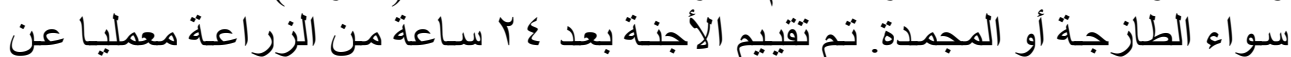

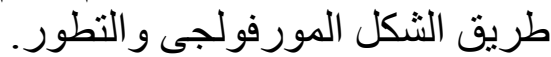

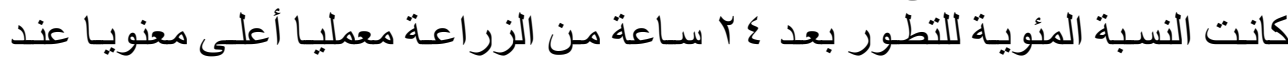

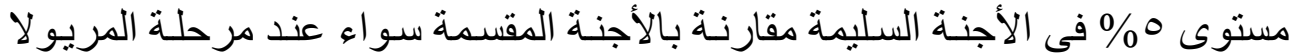

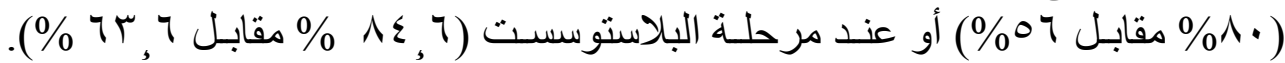

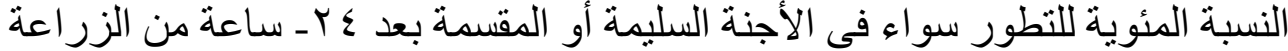

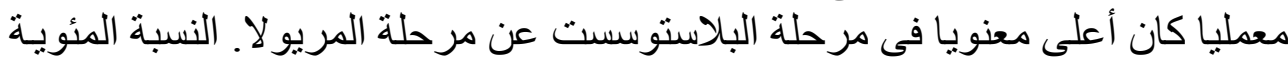

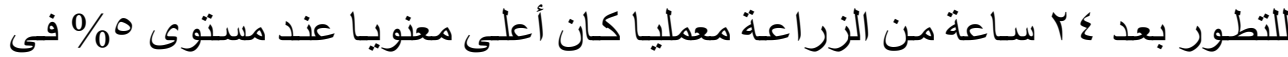

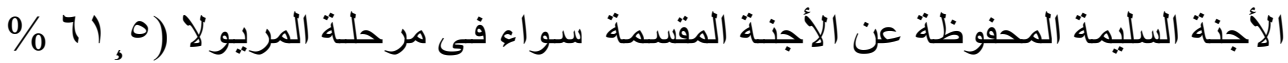

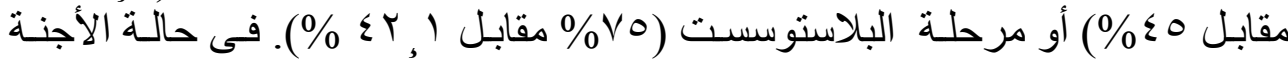

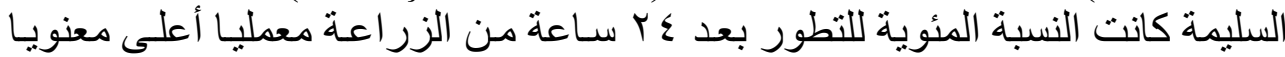

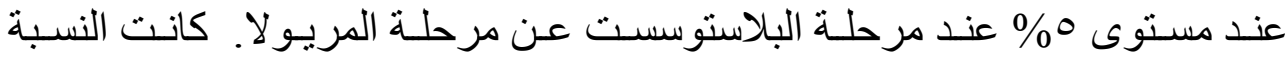

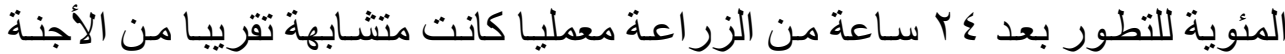

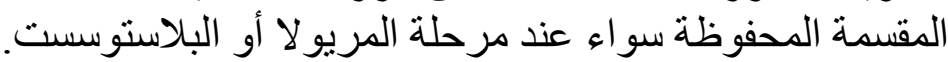

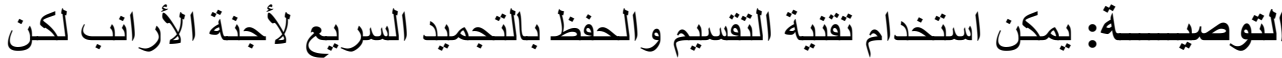
مرحلة التطور الجنينى وطريقة الحفظ تعتبر من العو امل المحددة فى ذلك. 